\title{
A clinica entre parênteses: reflexóes sobre o papel da arte e da militância na vida de usuários de saúde mental*
}

| ${ }^{1}$ Clarice Moreira Portugal, ${ }^{2}$ Martin Mezza, ${ }^{3}$ Monica Nunes |

Resumo: O artigo pretende discutir os efeitos transformadores dos contextos militantes e artísticos no cotidiano de usuários de saúde mental. Trata-se de uma pesquisa etnográfica, cuja metodologia envolveu observação participante e realização de entrevistas. A análise dos dados pautou-se na hermenêutica crítica e reflexiva e na perspectiva fenomenológica. Pudemos verificar que o engajamento em grupos artísticos e militantes repercute contundentemente nos mundos da vida dessas pessoas, bem como na elaboração de seu cotidiano. Nesses locais, dá-se a construção de relaçôes empáticas e de alteridade, cujo desenrolar se acentua no momento em que o grupo se encontra reunido, mas também possui repercussôes que ultrapassam esse intervalo espaço-temporal. Elementos performáticos e simbólicos contribuem para a reelaboração de um ser-no-mundo desses sujeitos e exigem dos envolvidos a construção de uma cena coletiva na qual são negociados papéis, funções, expectativas e afecções; e esse processo lhes permite acessar de novas posições toda uma diversidade de dramas sociais. É possível, assim, considerar esses espaços sob o viés terapêutico, porém, vimos que é justamente da negação desse estatuto que advém sua eficácia. Dessa forma, reforçamos a importância de espaços abertos ao protagonismo dos sujeitos para uma reforma psiquiátrica pensada enquanto processo social complexo.

> Palavras-chave: atenção psicossocial; clínica ampliada; saúde mental; arte; militância; Antropologia da Experiência.
* Financiamento FAPESB.

1 Instituto de Saúde Coletiva, Universidade Federal da Bahia. Salvador-BA, Brasil (clariceportugal@gmail.com). ORCID: 0000-0003-0373-4141

${ }^{2}$ Instituto de Saúde Coletiva, Universidade Federal da Bahia. Salvador-BA, Brasil (mezzamartin@yahoo.com.ar).

${ }^{3}$ Instituto de Saúde Coletiva, Universidade Federal da Bahia. Salvador-BA, Brasil (nunesm@ ufba.br).

Recebido em: 14/08/2017 Aprovado em: 18/03/2018 Revisado em: 14/05/2018 


\section{Introdução}

No campo da saúde mental, verifica-se uma literatura relativamente bem sedimentada acerca da clínica ampliada e dos efeitos transformadores de projetos artístico-culturais e políticos na vida de sujeitos em sofrimento psíquico.

A proposta da clínica ampliada, segundo a entendemos, tem por finalidades responder ao paradoxo entre loucura e razão (BIRMAN, 1992) e agir na cisão denunciada por Rotelli (2014) entre cuidado e reabilitação. Sua teoria e sua prática dirigem-se ao abismo que se abre entre a doença e o sofrimento psíquico, assim como para o sujeito - eclipsado na doença mental - em sua experiência concreta e cotidiana, em sua existência social (AMARANTE, 2007, p. 66). Dessa maneira, Campos (2002) e Lancetti (2005) destacam o entrelaçamento entre clínica e política e reclamam a urgente necessidade de invenção da clínica do cotidiano, assim como Desviat (2015) faz um apelo para a construção de uma psicopatologia vinculada aos princípios da Reforma. Dito de outro modo, propóem açóes que contemplem o sofrimento existencial dos sujeitos e sua relação com o corpo social.

Em oposição à causalidade linear, que levaria de alteraçôes biológicas ou físicas (impairment) até disfunçôes (disability), e destas até desvantagens sociais (handicap), Rotelli (2014) advoga por uma lógica circular de cuidado, segundo a qual, no caso da loucura, a desvantagem social de ocupar o papel de doente mental intervém de forma preponderante como causa de inabilidade. Seguindo um raciocínio semelhante, Nunes e Onocko-Campos (2014) destacam que a clínica ampliada em saúde mental deve contemplar o sujeito e sua singularidade no contexto do território e da sua complexidade; ao mesmo tempo que apontam para o recovery, a reabilitação social, a promoção da cidadania e da equidade.

Por outro lado, Onocko-Campos (2001, p. 99) observa certo direcionamento no pensamento sanitário hegemônico no campo da saúde coletiva no sentido de negligenciar a clínica. Para a autora, "[...] a dimensão social continua cindida, pois agora se pode olhar e até escutar as comunidades, mas elas não se encarnam em doentes concretos. Os cidadãos devem ser escutados; os doentes, nem tanto". Também Ayres (2001) faz a crítica à saúde coletiva para marcar impasses decorrentes da noçâo de sujeito e da razão instrumental no diálogo com a população que pretende transformar. Diante desse impasse, traz a premente necessidade de substituição da 
noção de sujeito pela de subjetividades, e da razão instrumental por projetos de felicidade, os quais devem orientar toda e qualquer relação de cuidado.

A arte, por sua vez, é reconhecida como outro vetor importante no empoderamento e incremento da agência dos usuários de saúde mental. Quanto a isso, vale citar os trabalhos do grupo de pesquisa de Sue Hacking (2006, 2008), que apontaram para um aumento significativo do empoderamento, da inclusão social e da saúde mental entre aqueles usuários ligados a intervençóes artísticas, e o impacto destas teve correlaçốes positivas com esses três fatores.

Amarante e Costa (2012, p. 47), porém, advertem que a conexão entre arte e saúde mental deve escapar às armadilhas da docilização e da imposição laborativa por si só enquanto intervenção clínico-terapêutica, deixando "de ser um meio terapêutico para serem um fim em si”. Nesse sentido, trata-se de pensar o campo artístico-cultural efetivamente conectado à atenção psicossocial e autonomamente afirmado na conquista de direitos e cidadania (AMARANTE et al., 2012). Da mesma forma, os movimentos sociais ligados à luta antimanicomial mais e mais têm se consolidado e obtido reconhecimento na esfera pública, bem como vêm contribuindo significativamente para as conquistas e o incremento dos direitos dos usuários de saúde mental (SANTOS, 2012).

Partindo desse arcabouço, pretendemos apresentar e discutir os efeitos transformadores de determinados contextos que não se restringem aos espaços de ação terapêutica institucionalizada, como grupos cênicos e associaçôes de militância pelos direitos dos usuários e familiares de saúde mental.

\section{Metodologia}

O nosso estudo inscreve-se entre os estudos da Antropologia da Experiência (TURNER; BRUNER, 1986), os quais compreendem que as experiências - sejam elas coletivas ou pessoais - só são acessadas a partir de suas performances e expressôes (narrativas, manifestaçóes artísticas, rituais, mitos, modos de cuidar etc.).

Tomando por base esse arcabouço, desenvolvemos um estudo qualitativo de caráter etnográfico nos moldes de uma Antropologia Implicada (NUNES, 2014), no município de Salvador, Bahia. A elaboração dessa etnografia incluiu a realização de entrevistas não estruturadas conjugadas à observação participante, bem como o registro de observaçôes, episódios, acontecimentos e relatos intrínsecos à experiência em diários de campo, a partir de uma descrição densa (GEERTZ, 1973). 
Escolhemos casos a ser acompanhados em profundidade a partir de três estratégias: 1) entrada em instituiçôes da rede de atenção psicossocial; 2) consulta a associaçôes de usuários de saúde mental, de moradores de rua e a líderes locais e religiosos; 3) observação participante em comunidades de estudo.

As entrevistas com os usuários ou outros informantes tiveram por finalidade a reconstrução compartilhada da trajetória dos interlocutores e o aprofundamento das questôes emergentes ao longo da observação participante, sendo eles mutuamente influenciados.

O acompanhamento de casos teve como princípio norteador a análise dos itinerários terapêuticos, dos modos de fazer do cotidiano, e a reconstrução das histórias de vida de pessoas com transtornos psíquicos severos com mais de seis meses de institucionalização. A condução do "acompanhamento participante" era elaborada caso a caso junto com os participantes e envolvia instâncias muito distintas, definidas por e a partir de suas próprias vidas.

Para tal fim, foi estabelecido um convívio mais cotidiano (aproximadamente por um ano) com os casos escolhidos nos espaços por eles franqueados à nossa inserção, incluindo família, vizinhança, profissionais, instituiçôes de cuidado, trabalho, espaços religiosos, de lazer, associativos etc. Neste artigo, apresentaremos casos inseridos em uma associação de usuários e familiares de saúde mental e de um grupo teatral também composto por usuários.-

Uma análise hermenêutica crítica e reflexiva (BIBEAU; CORIN, 1995) das narrativas produzidas e das práticas concretas observadas e reconfiguradas a partir da presença implicada dos pesquisadores foi empreendida. Pautamo-nos também em autores da vertente fenomenológica (SCHUTZ, 1967; SCHUTZ; LUCKMANN, 1973), de forma a elucidar os componentes performáticos, experienciais e simbólicos. Isso porque a compreensão das experiências é uma produção intersubjetiva que envolve a subjetividade de quem produz a expressão e a subjetividade de quem a interpreta (RICOEUR, 1976). Consideramos, ainda, as contribuiçóes de alguns expoentes do movimento da Reforma Psiquiátrica, como Amarante, Rotelli e Basaglia, bem como a teoria do reconhecimento de Axel Honneth.

Assim, tomamos as entrevistas e observaçóes de campo como textos, abordando sua semântica em busca das suas significaçôes. A interpretação foi realizada pela confrontação da potencialidade polissêmica do texto, mas também pela sua situação nos contextos de fala, culturais, sociais e históricos. Para tanto, analisamos as 
metáforas vivas presentes no texto e os conteúdos simbólicos relevantes para os sujeitos e para o grupo, alinhados aos relatos e observações da vida cotidiana.

Inicialmente, predefinimos dimensóes de análise que foram desmembradas em um conjunto de categorias éticas que serviram como analisadores dos processos de desinstitucionalização (NICÁCIO, 1990; LEAL; DELGADO, 2007): equidade e desigualdade sociais; autonomia, empoderamento e constrangimento; integralidade e fragmentação do cuidado; e experiência e narrativa de adoecimento.

Essas dimensóes constituíram uma primeira matriz analítica no programa de análise de dados qualitativos NVivo $8.0^{\circ}$, por meio do qual categorizamos as transcrições de entrevista e diários de campo. Esse trabalho deu-se pari passu às reunióes semanais do grupo de pesquisa, com fins a criar "interpretaçóes das interpretaçôes" que permitissem à "fusão de horizontes" (GADAMER, 1977) se produzir durante as discussôes do grupo e ganhar substância no corpo da análise. Ao cabo desse processo, o software emitiu relatórios específicos a cada uma das dimensôes supracitadas, cotejando-as ao material empírico bruto e às novas compreensóes geradas em nossas discussóes coletivas.

Realizamos uma leitura pormenorizada desses relatórios, que nos permitiu chegar a outras categorias derivadas do processo reflexivo em curso. A partir disso, foi elaborada uma segunda matriz de análise que reagregou os elementos discutidos em cada um dos relatórios em tabelas tripartite, organizadas da seguinte maneira: a primeira coluna designa subdivisóes e/ou subtemas abordados na tabela - referentes às categorias êmicas e éticas inter-relacionadas, essas temáticas são híbridos derivados da discussão dos dados empíricos e da leitura teórica; uma segunda coluna com as interpretaçôes e indagaçôes dos pesquisadores, onde também inserimos alusôes a autores e citaçóes que se mostraram pertinentes; e uma terceira composta por recortes do trabalho de campo. Desse modo, foi possível dar concretude à produção hermenêutica, iluminando a polifonia inerente aos textos culturais, bem como as inconsistências, lacunas e heterogeneidades que os constituem.

Todos os participantes foram devidamente esclarecidos sobre sua participação no estudo e assinaram o Termo de Consentimento, de acordo com a declaraçáo de Helsinski da Associação Médica Mundial e a Resolução 466, de 2012. Seus nomes e de outrem (pessoas e situaçôes) que poderiam levar à sua identificação foram substituídos e a pesquisa a que o presente artigo se vincula foi aprovada pelo Comitê 
de Ética em Pesquisa do Instituto de Saúde Coletiva, Universidade Federal da Bahia, sob o parecer $n^{\circ}$ 023-12- CEP-ISC.

\section{Resultados e discussão}

Em nossas análises, verificamos que o engajamento em grupos artísticos e militantes repercute contundentemente nos mundos da vida (SCHUTZ; LUCKMANN, 1973) dessas pessoas e nos daqueles que os rodeiam, bem como na elaboração do seu cotidiano. Reconhecendo as profundas diferenças entre os dois tipos de enquadramentos, em termos de seus objetivos e de seu funcionamento, pudemos perceber que em ambos se dá a construção de identidades, de relações empáticas e de reconhecimento, de alteridade, assim como de elementos simbólicos e experienciais intimamente ligados à performance - cujo desenrolar se acentua no momento em que o grupo se encontra reunido e/ou envolvido em alguma atividade, mas também possui repercussóes que em muito ultrapassam esse intervalo espaço-temporal.

Nesse sentido, resgatamos a leitura de Turner (1992) acerca dos rituais para pensar os principais eventos possibilitados a esses atores por meio dessas inserçôes. Em sentido semelhante, consideramos as contribuiçôes de Goffman (1982) acerca da análise dos espaços teatrais, nos quais o engajamento na estabilidade de uma "face" elabora-se por meio de uma cooperação ritualística.

Grupos artísticos e militantes de usuários de saúde mental incorporam em sua vida sociocultural práticas que tendem à liminaridade (VAN GENNEP, 2011) e/ ou podem ser mais bem entendidas como liminoides - no sentido de que não são exatamente, mas se assemelham aos fenômenos liminares que, como nos lembra Turner (2012), inserem os sujeitos neles envolvidos em uma situação transitória e socialmente ambígua, mas com potencial para ampliar o espaço social e romper com o status quo, assim como para provocar a transformação subjetiva dos sujeitos que deles passam a fazer parte. Criam, por vezes, uma espécie de refúgio, ou para continuar usando os termos de Turner (1992), uma espécie de communitas entendida aqui enquanto uma forma de antiestrutura constituída pelos vínculos entre indivíduos e/ou grupos sociais que compartilham uma condição liminar em momentos ritualizados para além de uma circunscrição espacial ou pertencimento territorial preestabelecido. 
A imersão tanto na militância em saúde mental quanto no grupo cênico parece envolver toda uma ritualização. Ritualizaçáo esta que pode ser pensada no sentido lato, enquanto participação em um grupo cuja inclusão exige certa separação a que se segue uma reagregação à sociedade mais ampla; quanto no sentido estrito, na medida em que ambos os circuitos fazem uso de certas ritualísticas nos seus encontros, cujos simbolismos e afecçôes fazem-se patentes, como se pode ver nos trechos de diário de campo a seguir:

Antes da peça começar deu-se um tipo de ritual do qual fui convidada a participar. Nem todos os envolvidos participaram, mas todos os que estavam presentes, incluindo eu, fizemos uma roda e fazíamos diversos alongamentos e movimentos com o corpo. Por exemplo, em um dado momento pegávamos na bunda de quem estava tanto à esquerda quanto à direita de nós, o que claramente servia para aumentar a intimidade e a conexão entre todos ali. [...] Ao final, todos se abraçaram e correram em direção ao meio do círculo para gritar uma palavra - a escolhida naquele dia foi "amor" (Diário de campo).

Antes do início das atividades [da reunião de militância] propriamente ditas - ainda que as pautas sejam discutidas bem antes do começo simbólico - é feita uma oração "ecumênica” guiada por Carlos, que pede paciência para suportar o que não se pode mudar, coragem para mudar aquelas que se pode mudar e sabedoria para distinguir umas das outras, tal qual aquela que inicia as reunióes dos Alcoólicos Anônimos (Diário de campo).

Dessa forma, a liminaridade e a gênese de uma communitas parecem ser um elo comum a esses dois contextos, o que permite aos seus membros o compartilhar de uma experiência muito própria de estar no mundo, que passa a caracterizá-los a um só tempo enquanto sujeitos e enquanto grupo. Apreendem-se daí formas ritualísticas que encerram um domínio especial de ação, que colocam em suspenso os parâmetros da vida cotidiana e com as subjetividades definidas pelos espaços clínicos tout court, demandando de seus participantes uma mudança de atitude e atenção. $\mathrm{O}$ sucesso do ritual está justamente em sua capacidade de "transportar" os presentes através dessa sucessão de enquadres e reaçôes correspondentes (LÉVI-STRAUSS, 1967). Tratar dos processos imaginativos desenrolados durante os rituais é justamente dar conta dos modos pelos quais os participantes se envolvem e assumem enquanto seus os enquadres engendrados.

Tornar-se um ator ou militante no contexto da luta antimanicomial no Brasil, de certa forma, diz respeito a uma (re)inserção cultural e social, cujas transformaçôes repercutem na vida desses sujeitos para além desse nicho. Como observaremos mais detidamente a seguir, a "peça” teatral ocupa um lugar material e simbólico de suma importância no cotidiano de Lázaro, que, além de possibilitar vínculos afetivos e 
experiências de expressão corporal e emocional, oferece uma descontinuidade com a subjetividade de doente mental. A possibilidade de "se recolher", ou seja, de se afastar um pouco das exigências do cenário e da fachada do cotidiano da doença mental já não são exigências exclusivas e impostas desde os domínios da normatividade manicomial; o ofício de ator demanda uma (re)inserção ritualística em que esse momento de recolhimento é mais uma etapa, como podemos ver abaixo:

\section{[...] fala bastante sobre a peça da próxima segunda-feira, sobre como precisa a partir de agora se concentrar e começar a entrar em Gretchen, sua personagem na peça [...] vai se "re- colher” nos próximos dias "para trabalhar sua personagem” (Lázaro - Diário de campo).}

Sem negar o sofrimento nem a singularidade implicada na pessoa que dele padece, os espaços aqui considerados (teatro e militância) apresentam um caráter ritualístico de potencial liminar que contribui para a suspensão da institucionalização da doença mental. $\mathrm{O}$ intervalo temporal em que o sujeito se encontra no limiar entre modos diferentes e potenciais de existência (deixar de ser doente mental para ser ator, deixar de ser Lázaro para ser Gretchen), aqui marcado pelo significante "recolher”, articulase às relaçôes sociais suportadas nos espaços de teatro e militância. Está em jogo aqui, em certa medida, o desconstruir a institucionalização da "fachada" de doente mental, para poder entrar em outra "personagem", em outro "cenário", e assim poder, a partir de todo um "equipamento expressivo", "executar outra representaçáa" (GOFFMAN, 2001).

Mas nem sempre essas diversas histórias e múltiplas identidades se articulam de forma harmônica ou num enredo homogêneo; embora muitas vezes sejam complementares, por vezes se opõem, entram em conflito ou se fragmentam. O último recorte trazido da entrevista de Lázaro evidencia uma narrativa caracterizada pela multiplicidade e conflito entre as subidentidades, "eus" parciais ou fachadas, se tomamos o dizer de Goffman (ibid.). O interessante de salientar é que podemos perceber a presença de um sujeito, do seu sofrimento, tanto quanto o jogo de identidades: louco, doente, ator e conselheiro.

Eu passei a dizer que isso estava errado e que eu mesmo, dentro da minha descompensação [refere-se à ideação suicida], eu pensei: "está errado. Você representante, fazer tudo que eu faço, como é que eu vou fazer isso se eu sou representante dos usuários de saúde mental? Quando eu melhorar, me falam o tempo todo que quando eu melhorar querem ser igual a mim. Por que que eu vou fazer isso? Eu não vou prejudicar só a mim, ao serviço, os meus familiares que não eram do meu lado e agora já estão se aproximando de mim. A comunidade me tacava pedra, me denegria. Hoje eu sou o conselheiro de uma comunidade e represento o meu bairro... Sou um dos conselheiro distrital" (Entrevista - Lázaro). 
Esse enredo de subidentidades (MISHLER, 2002) também pode ser considerado e enriquecido quando levamos em conta a perspectiva de Schwalbe (1993), que distingue entre sujeito (self) e identidade. Aqui, o sujeito encontra-se ligado a processos psicobiológicos modelados por signos e símbolos e vinculados a aspectos de resistência e escolha; enquanto a identidade se entende como um construto de significados ligados à biografia pessoal, às interaçóes sociais e às experiências culturalmente significativas que podem desaparecer e modificar-se em função das interações sociais.

A teoria do reconhecimento de Honneth (2003), mesmo mantendo a precedência da percepçáo - reconhecimento - do outro sobre o desenvolvimento da autoconsciência, recorre à divisão entre "Eu" e "Mes" (aportado por George Mead), com o intuito de trazer a dialética e o conflito entre a interiorização normativa da coletividade e o "reservatório de energias psíquicas que dota o sujeito de um grande número de possibilidades inesgotadas de identidade" (ibid., p. 140). Finalmente, as elaboraçôes de Goffman (1963) colaboram também para pensar o processo de construção e reconstrução permanente da identidade, ao distinguir entre identidades sociais, de ego e pessoal.

Afinando-nos a esses autores, percebemos uma pluralidade no terreno identitário com a qual se abre uma janela de negociação entre esses diversos papéis e sua repercussão na elaboração do eu-em-sofrimento. Lázaro brinda-nos com um questionamento acerca de sua condição de sujeito em crise, incoerente (segundo sua própria percepção) com suas demais identidades que, mesmo sem anular por completo sua dor, permitem-lhe pensar sobre ela, interferindo na sua experiência.

O efeito terapêutico vinculado ao enredo de múltiplas identidades (representado de forma pontual no modo de Lázaro lidar com a descompensaçáa) é testemunho da dialética entre a performance de um sujeito (em sofrimento) e a ampliação das interaçóes sociais e de reconhecimento. Uma clínica que se faz em ato e na vida - ou peripateticamente, como nos lembra Lancetti (2005).

Essa transformação identitária acaba também por ensejar novas formas de agir e estar no mundo, como podemos ver a seguir:

Saía, ia pra calçada, ia pro motel, aí eu transava com eles e voltava com dinheiro, e eu não achava dignidade em mim. Logo eu, que fui uma mulher que foi tão violentada dentro de sanatório e tudo, viver essa vida, eu não achava legal. Aí eu disse não, eu vou fazer da militância o meu trabalho, vou fazer meus artesanatos e levar pra militância, começar a militar de verdade (Entrevista - Rosa). 
Em sentido semelhante, Aurora mostra como a inserção no movimento social auxiliou-lhe a dividir o "peso" do estigma da doença mental e a "transportar-se" para outros "enquadres" (LÉVI-STRAUSS, 1967). A conexão com os demais militantes e a identificação com suas experiências trouxeram-lhe outra perspectiva, a partir da qual pôde envolver-se em relaçôes empáticas, e ao comungar do grupo militante, foi possível a ela lidar de forma mais positiva com sua própria condição.

comecei a voltar à ativa, foi quando eu conheci também a Associação [...] Aí fui me envolvendo [...] e aí comecei a tá contactando com a Associação e isso foi me ajudando também a me envolver [...] a esquizofrenia pra mim era como um câncer, era um palavrão muito pesado, um palavrão não, uma palavra muito negativa, mas à proporção que eu fui convivendo na Associação e na saúde mental, conhecendo pessoas que tinham os sintomas e as características minhas... (Entrevista - Aurora).

Tanto Rosa quanto Aurora demonstram que o engajamento em espaços de militância e resistência, além de lutar por futuros padróes ampliados de reconhecimento, tem por efeito presente liberar os participantes das situaçóes de rebaixamento "passivamente" toleradas e possibilitar uma autorrelação nova e positiva (HONNETH, 2003, p. 259).

Seguindo esse raciocínio, resgatamos a segunda acepção vislumbrada por DaMatta (2000) acerca dos ritos de passagem elucidados por Van Gennep (2011), cuja

[...] novidade consiste, precisamente, em tomar o simbolismo dos ritos de passagem como uma dramatização de valores, axiomas, conflitos e contradiçóes sociais. Trata-se de mostrar que o ponto de vista deslocado, salientado na liminaridade, não configurava situações, processos ou papéis meramente pecaminosos, patológicos e criminosos, mas que era inerente à própria sociedade humana. Como sempre, a descoberta da positividade dos estados liminares e a discussão de sua importância como elemento essencial da constituição da própria sociabilidade, colocavam em crise os modos tradicionais de se discutir a marginalidade como um estado potencialmente criminoso, bem como o desvio como pré-patologia ou perversão. Ademais, elas abriam a possibilidade de enfatizar a "licença ritual", esses momentos especiais opostos às prescriçóes político-legais, nos quais a sociedade se permitia ler-se a si própria de ponta-cabeça (DAMATTA, 2000, p. 12).

Nos tipos de espaços supracitados são marcantes os elementos performáticos e simbólicos que, em última instância, não só contribuem para a reelaboração de um ser no mundo desses sujeitos há muito à margem no contexto ocidental(izado), mas também exigem dos envolvidos a construçáo de uma cena coletiva na qual são manejados e negociados papéis, funções, expectativas e afecçôes, que lhes permitem acessar toda uma diversidade de dramas sociais até então inacessíveis ou impensáveis para esses sujeitos. 
À parte as semelhanças no sentido do pertencimento e da densificação dos vínculos entre os membros dos referidos grupos, é preciso frisar que do ponto de vista performático é possível observar algumas nuances. Se na performance de ator e na performance de militante há um script a ser realizado, na militância torna-se patente sua execução enquanto drama social (TURNER, 1992a), o que hipoteticamente pode não ser tão evidente no grupo de encenação teatral, na medida em que o próprio teatro traz em seu bojo o processo de construção do roteiro e das performances a ser desempenhadas.

Essa construção, porém, atualiza uma série de conflitos e experiências, o que fica claro em um espetáculo do grupo em questão, no qual são teatralizados fragmentos das suas histórias de vida, que ganham outra conotação distinta da vida cotidiana. Isso porque o drama teatral, mais do que entreter, pode se mostrar como um metacomentário mais ou menos consciente acerca dos dramas sociais maiores desse contexto social. Nesse sentido, entremeia-se aos dramas sociais maiores, de maneira que seu conteúdo e sua retórica retroalimentam o drama social e acabam por contribuir para a sua ritualização (ibid., p. 107-108).

Percebemos que tanto o teatro quanto as associaçóes de luta política no seu vivenciar englobam a gênese de uma fase liminar a partir (e dentro) da qual as mais diversas experiências tornam-se possíveis; no entanto, no espaço militante mostra-se urgente a resolução dos conflitos e demandas que permitem a emergência da luta política enquanto drama e que se colocam como questóes necessárias e passíveis de resolução na vida "real". Isso não impede, porém, que contemplemos o dinamismo e mesmo a complementaridade desses dois espaços de concepção e exercício do drama. Desses dois modos de atuaçáo - na vida e no palco -, podemos apreender componentes de um sistema dinâmico de interdependência entre os dramas sociais e as performances culturais.

Se tomarmos para o nosso estudo a explicação de Victor Turner sobre esse ciclo em que a vida, mais do que imitar, torna-se arte, é possível vislumbrar que as demandas que a vida de um usuário de saúde mental impóe são elaboradas nos textos e encenaçôes; e dessas encenaçôes produzem-se reelaboraçôes dessas mesmas demandas, que são negociadas e atuadas no espaço militante; e dali emergem desfechos, desejos e ensejos que emergirão em novas matizes e sons na criação das peças e em suas encenaçôes. Por essa linha de pensamento, compreendemos que tanto a militância quanto o teatro são arenas de elaboração de identidades nas quais 
as formas de elaboração de discursos, de negociação e elaboração da alteridade são permanentemente (re)feitas.

Outro ponto importante e com repercussôes significativas na vida dos atores e militantes ligados ao campo de saúde mental diz respeito à sua elaboração performática. Toda e qualquer performance tem em seu cerne uma ação ritual que demanda uma mudança comportamental (SCHECHNER, 1988), ainda que de forma permanentemente inacabada, como um "paradigma em curso" (ibid., p. 8).

Pensar nas performances engendradas na militância e no teatro exige, entretanto, refletir sobre os diferentes tipos de atividade e graus de publicização das mesmas. No âmbito público, temos as apresentaçoes, passeatas e protestos; já no âmbito privado (com uma pequena abertura pública, vale dizer), temos as reunióes de militância e ensaios. Naqueles considerados mais públicos e que exigem o contato com membros externos ao grupo e a criação de uma nova roupagem para discursos e desejos mais ou menos consolidados, como se pode ver abaixo:

Otávio me ensinou que eu podia ser livre, mas que eu não podia bater em ninguém, que
eu era uma usuária muito, muito louca [...] a primeira vez que ele me leva pro movimento
lá em noventa e três como eu já falei, que eu tiro a roupa e fico nua, porque tava falando
e ninguém ligou, ai tirei a roupa e comecei a pular em cima da mesa onde as pessoas
"tava" falando e todo mundo começou olhar pra mim e me escutou. Ele vem de lá e veste
minha roupa e diz: mulher, você tá louca, tá louca? [...] Tá vendo que tem que ser de outra
forma, e eu comecei a tentar ser de outra forma, passando muitas dificuldades, porque
as pessoas náo acreditavam no que a gente fala né, quando eu era estuprada dentro do
sanatório pelo médico psiquiatra, eu dizia e eles dizia que era mentira, tá maluca, ela é
maluca (Entrevista - Rosa).

Vemos ainda que o início da carreira militante pode vir da mais fragmentadora e excludente experiência, como nos mostra o depoimento de Rosa a partir das experiências de desrespeito (HONNETH, 2003) na vida cotidiana ou no interior das instituições totais (GOFFMAN, 1974). A história de vida contida - reconstruída - nessa narrativa não apresenta uma lógica linear exprimida na concepção mais dura de reabilitação, qual seja, a estabilização do "quadro" como prerrogativa para a inserção social (normatização). Se a demanda de mudança de comportamento não está no primeiro plano - por aparecer em primeiro plano a decisão espontânea do sujeito -, na substituiçáo que implica a venda dos artesanatos no lugar da venda do corpo, a intervenção das exigências do meio social aparece em toda sua inteireza na interação com o líder militante Otávio. A nudez não atrai a atenção da audiência e 
tampouco torna seu discurso legítimo e ou lhe garante um lugar de fala. O corpo nu que demandava o olhar do público, foi (re)vestido e interpelado. Há uma intervenção que a reenquadra e afirma a premência do social e de suas exigências.

Nesses distintos enquadres é exigida essa recriação comportamental que se atualiza a cada situação a ser compartilhada pelos grupos. Criam-se, inclusive, certos scripts que podem, a um primeiro olhar, ser interpretados como eminentemente disciplinares; vistos com mais atenção, parecem dizer respeito à relação entre atores e públicos do drama social, na qual a criação de uma representação (papel) tende a dar credibilidade à realidade representada (GOFFMAN, 2001).

Talita, ela fez bem de impor o respeito [...] [Talita:] "Eu sou sua diretora teatral. Vocês são artistas. Aqui eu não estou lidando com usuário de saúde mental” Ela deixa bem claro. Ela fala com a gente, daqui a pouco ela dá uma bronca educadíssima e nós, todo mundo obedece. Nenhum técnico em nenhum manicômio fez a... teve a coragem que essa menina teve. Eu tiro o meu chapéu (Entrevista - Lázaro).

O depoimento de Lázaro mostra com clareza algumas sutilezas da relação com sua diretora teatral, Talita. É interessante perceber que ela, psicóloga e atriz, faz questão de afirmar o espaço do grupo como não clínico. Ela ressalta que ali não é um local de tratamento e que, por isso, é preciso ter uma atitude profissional, o que exige deixar de lado diferenças pessoais e outras queixas e demandas que possam vir a interferir na qualidade do ensaio e, consequentemente, da própria peça. E é justamente essa negação que vem contribuir para a eficácia terapêutica, independentemente de ser colocada como propósito do grupo.

Toda essa "realização dramática" e "idealização" tem por objetivo atingir uma "eficácia da representação" (GOFFMAN, 2001) em que se possa diferenciar uma oficina de teatro com usuários de saúde mental e um grupo de teatro com atores. Essa afirmação da veridicidade da posição e da máscara social de ator permite-nos ver, todavia, por parte do ator (neste caso, a diretora) e do público (neste caso, os atores) um atuar sincero, já que os atores se encontram comprometidos e acreditam na realidade representada. Afirmar o lugar de ator, o reenquadramento da antiga psicóloga no lugar de diretora e dos até então pacientes/padecentes em atores/agentes é parte da ritualística do grupo e contribui para a criação de uma nova situação e de um espaço para que o novo possa surgir, seja diante do público, seja diante do espelho:

No Festival Americano de teatro, nós fomos quase um que fizemos recorde de público. Nego matando pra entrar... cada dia foi duzentas, trezentas pessoas que conseguia entrar. Aí eles não conseguiram, grandes... os artistas profissional. E depois um bate papo com 
todo mundo chorando. Eles chorando e nós sentado assim atrás. Como é que nós ia chorar com a nossa história? Porque é incrível. [...] Muitos teatros não conseguem isso. $\mathrm{O}$ glamour foi grande (Entrevista - Lázaro).

Diante da possibilidade de se fazer ouvir e ver por uma prestigiosa audiência, a exposição das narrativas carregadas de dor e sofrimento dos atores permite-lhes reinterpretar a própria trajetória e contemplá-la desde outro lugar. Essa elaboração conjunta viabiliza criar um espaço em que o eu e o outro se confundem, de tal forma que o afeto vivido e comportado na memória emerge com força na experiência daqueles que, ao serem confrontados com tais dramas, tornam-se, em alguma medida, também atores. Do e no compartilhar de histórias faz-se a empatia e a possibilidade de, a um só tempo, uma catarse e uma ressignificação de experiências que vêm permitir a gênese de novas relações sociais entre sujeitos ligados a contextos sociais tão distintos.

\section{Considerações finais}

A partir de nossos achados, vimos que é possível considerar os espaços cênicos e militantes sob o viés terapêutico. Por meio da intrincada relação entre o caráter ritualístico e as performances desempenhadas nesses locais - estando estas alinhavadas ao protagonismo dos sujeitos nas diversas interaçôes sociais, à suspensão e reconstituição de identidades e à dinâmica de reconhecimento da vida social -, destacamos a conformaçáo de direitos e cidadanias como um efeito terapêutico: alívio de sofrimento, ressignificação das histórias, empoderamento e autonomia, reinvençâo do cotidiano e elaboração de novas modalidades de lidar com a alteridade.

Este efeito terapêutico se dá no cerne de espaços caracterizados como não clínicos, onde se enfatizam os traços de autonomia e independência com o discurso técnico-científico hegemônico sobre a loucura; discurso este, por vezes, embutido em lógicas de atenção em saúde mental que fazem uso do enquadramento da arte como recurso terapêutico, conectando-se a uma concepção de cultura como restrita à arte institucionalizada, segundo enunciado por Amarante et al (2012a).

Assim como colocar a doença entre parênteses não supóe rejeitar o específico do sofrimento psíquico, e sim suspender a construção ideológica que, principalmente, a psiquiatria constrói sobre ele; suspender a clínica, colocá-la entre parênteses, não significa outra coisa senão produzir a ruptura com uma ação que apassiva e 
dociliza corpos, que exclui das interaçóes sociais, dos direitos e da cidadania, e que, perante aqueles que demandam - ou não - cuidados, responde com um projeto preestabelecido e marcado pela tutela. Longe de rejeitar a clínica ou a terapêutica, a suspensão apresentada neste trabalho pretende contribuir para melhor operar nas continuidades e descontinuidades estruturais e históricas da loucura-doença. Se consideramos, tal qual Basaglia, que o terapêutico em saúde mental implica "viver dialeticamente as contradiçóes do real” (BASAGLIA, 2005, p. 115), vemos que ele se insere em um circuito paradoxal no qual é simultaneamente refutado e executado (BASAGLIA, 1985, p. 315-316).

A vida que se impóe e se atualiza nos contextos aqui estudados e na sua ritualística - pensada aqui não como repetição à exaustão de protocolos, mas como nichos de criação simbólica e performática - permite-nos vislumbrar um importante compromisso para a atenção psicossocial. Dessa forma, destacamos a importância de espaços abertos ao protagonismo dos sujeitos para uma reforma psiquiátrica pensada enquanto processo social complexo; mas por meio de uma dupla tarefa: incluindoos na clínica ampliada sem, no entanto, reduzi-los à clínica. Reforçamos, dessa maneira, o estabelecimento de um movimento dialético, um intercurso permanente entre clínica e cotidiano, ao tempo que a atenção psicossocial supõe a abertura a um ponto exterior à clínica, cujos efeitos podem e muitas vezes contribuem para enriquecê-la. Dito de outro modo, esses efeitos benéficos que destacamos em nosso estudo podem (e devem) ser considerados pelos profissionais de saúde mental e embasar a construção dessa clínica ampliada.

É certo, todavia, que não se pode desprezar o risco de tudo ser fagocitado em nome da clínica, quando o mundo-da-vida traz em si uma série de outros elementos que podem ser benéficos, e não precisam ser medicalizados ou incorporados pelo discurso da saúde._Para tanto, é certo, é preciso também um exercício por parte daqueles que são e fazem a clínica: a árdua e incessante tarefa de se afirmar como "parte dessa gente que pensa que a rua é a parte principal da cidade” (LEMINSKI, 2013, p. 24). ${ }^{1}$

\section{Referências}

AMARANTE, P. Saúde mental e atenção psicossocial. Rio de Janeiro: Fiocruz, 2007.

Ensaios: Saúde mental, subjetividade, sociedade. 3. ed. Rio de Janeiro: Editora Fiocruz, 2012. 
AMARANTE, P.; COSTA, A. M. Diversidade cultural e saúde. Rio de Janeiro: CEBES/ ABRASME/OPAS, 2012.

AMARANTE, P. et al. Da diversidade da loucura à identidade da cultura: o movimento social cultural no campo da reforma psiquiátrica. Cad. Bras. Saúde Mental, v. 4, n. 8, p. 125-132, 2012.

AMARANTE. P. et al. Da arteterapia nos serviços aos projetos culturais na cidade: a expansão dos projetos artísticos-culturais da saúde mental no território. In: AMARANTE, P.; CAMPOS, F. N. (Org.). Saúde Mental e Arte - Práticas, Saberes e Debates. São Paulo: Editora Zagodoni, 2012a, p. 23-38.

AYRES, J. R. de C. M. Sujeito, intersubjetividade e práticas de saúde. Ciência e Saúde Coletiva, v. 6, n. 1, p. 63-72, 2001.

BASAGLIA, F. A instituição negada: relato de um hospital psiquiátrico. Rio de Janeiro: Graal, 1985.

. As instituiçóes da violência. In: AMARANTE, P. (Org.). Escritos selecionados em saúde mental e reforma psiquiátrica. Rio de Janeiro: Garamond, 2005, p. 91-132.

BIBEAU, G.; CORIN, E. From submission to the text to interpretative violence. In: BIBEAU, G.; CORIN, E. E. (Orgs.). Beyond Textuality. Asceticism and Violence in Anthropological Interpretation. Approaches to Semiotics Series. Berlim: Mouton de Gruyter, 1995, p. 3-54.

BIRMAN, J. A cidadania tresloucada - notas introdutórias sobre a cidadania dos doentes mentais. In: BEZERRA, B.; AMARANTE, P. (Org.). Psiquiatria sem Hospicio - contribuiçóes ao estudo da reforma psiquiátrica. Rio de Janeiro: Relume-Dumará, 1992, p. 71-90.

CAMPOS, G. W. S. A Clínica do Sujeito: por uma clínica reformulada e ampliada. 2002. Disponível em: <http://www.pucsp.br/prosaude/downloads/bibliografia/CLINICAampliada. pdf>. Acesso em: 2 mar. 2016.

DAMATTA, R. Individualidade e liminaridade: consideraçóes sobre os ritos de passagem e a modernidade. Mana, v. 6, n. 1, p. 7-29, 2000.

DESVIAT, M. A reforma psiquiátrica. 2. ed. Rio de Janeiro: Fiocruz, 2015.

GADAMER, H. G. Semantics and Hermeneutics. In: . Philosophical Hermeneutics. Berkeley: University of California Press, 1977, p. 82-94.

GEERTZ, C. Thick description. Toward an interpretative theory of culture. In: . The interpretation of cultures: selected essays. New York: Basic Books, 1973, p. 3-30.

GOFFMAN, E. Manicômios, prisóes e conventos. São Paulo: Perspectiva, 1974.

. On face work. An analysis of ritual elements in social interaction. In: Interaction

ritual: Essays on face-to-face behavior. Nova York: Pantheon Books, 1982, p. 5-46. 
Representaçôes. In: . A representação do eu na vida cotidiana. Petrópolis: Editora Vozes, 2001, p. 25-75.

Stigma: notes on the management of spoiled identity. Englewood Cliffs, New Jersey: Prentice-Hall, 1963.

HACKING, S. et al. Mental health and arts participation: the state of the art in England. $J R$ Soc Promot Health, v. 126, n. 3, p. 121-127, 2006.

. Evaluating the impact of participatory art projects for people with mental health needs. Health Soc care Community, v. 16, n. 6, p. 638-648, 2008.

HONNETH, A. Luta por reconhecimento: a gramática moral dos conflitos sociais. São Paulo: 34, 2003.

LANCETTI, A. Clínica Peripatética. São Paulo: Hucitec, 2005.

LEAL, E. M.; DELGADO, P. G. G. Clínica e cotidiano: o CAPS como dispositivo de desinstitucionalização. In: PINHEIRO, R. et al. (Orgs.). Desinstitucionalização na saúde mental: contribuiçôes para estudos avaliativos. Rio de Janeiro: CEPESC: IMS/LAPPIS: ABRASCO, 2007, p. 137-154.

LEMINSKI, P. Toda Poesia - Paulo Leminski. São Paulo: Companhia das Letras, 2013.

LÉVI-STRAUSS, C. Antropologia Estrutural. Rio de Janeiro: Tempo Brasileiro, 1967.

MISHLER, E. G. Narrativa e identidade: a mão dupla do tempo. In: LOPES, L. P. M; BASTOS, L. C. (Org.). Identidades. Recortes multi e interdisciplinares. Campinas: Mercado de Letras (CNPq), 2002, p. 97-119.

NICÁCIO, M. F. (Org.) Desinstitucionalização. São Paulo: Hucitec, 1990.

NUNES, M. de O. Da aplicação à implicação na antropologia médica: leituras políticas, históricas e narrativas do mundo do adoecimento e da saúde. Hist. Cienc. Saúde-Manguinhos, v. 12, n. 2, p. 403-420, 2014.

NUNES, M. O.; ONOCKO-CAMPOS, R. T. Prevenção, Atenção e Controle em Saúde Mental. In: PAIM, J. S.; ALMEIDA-FILHO, N. (Org.) Saúde coletiva: teoria e prática. Rio de Janeiro: MedBook, 2014, p. 501-512.

ONOCKO-CAMPOS, R. Clínica: a palavra negada - sobre as práticas clínicas nos serviços substitutivos de Saúde Mental. Saúde em Debate, v. 25, n. 58, p. 98-111, 2001.

RICOEUR, P. Interpretation theory: discourse and the surplus of meaning. Fort Worth: Texas Christian University Press, 1976.

ROTELLI, F. Vivir sin Manicomios. La experiencia de Trieste. Ciudad Autónoma de Buenos Aires: Topía Editorial, 2014. 
SANTOS, M. R. P. Juntos na Luta: a trajetória de uma associação de usuários e familiares dos serviços de saúde mental na cidade de Salvador, Bahia. 2012. Dissertação (Mestrado em Ciências Sociais) - Universidade Federal da Bahia, Faculdade de Filosofia e Ciências Humanas, Salvador, 2012.

SCHECHNER, R. Victor Turner's last adventure. In: TURNER, V. The anthropology of performance. New York: PAJ Publications, 1988, p. 7-20.

SCHUTZ, A. Phenomenology of the social world. Evanston: Northwestern, 1967.

SCHUTZ, A.; LUCKMANN, T. The structures of the life-world. Evanston: Northwestern University Press, 1973.

SCHWALBE, M. Goffman against postmodernism: emotion and the reality of the self. Symbolic interaction, v. 1, n. 4, p. 333-350, 1993.

TURNER, E. Experiencing Ritual. Philadelphia: University of Pennsylvania Press, 1992.

TURNER, V. From ritual to theatre: the human seriousness of play. New York: PAJ Publications, 1992a.

- Liminal ao liminoide: em brincadeira, fluxo e ritual - um ensaio de simbologia comparativa. Mediaçôes - Revista de Ciências Sociais, v. 17, n. 2, p. 214-257, 2012.

TURNER, V.; BRUNER, E. M. (Org.). The Anthropology of Experience. Chicago: University of Illinois Press, 1986.

VAN GENNEP, A. Os ritos de passagem. 2. ed. Petrópolis: Vozes, 2011.

\section{Notas}

${ }^{1}$ C. M. Portugal e M. Mezza participaram da concepção, projeto, análise dos dados e redação do artigo. M. O. Nunes realizou a revisão crítica relevante do conteúdo intelectual e aprovação final da versão a ser publicada. 


\section{Abstract}

\section{The clinic between brackets: reflections on the role of art and militancy in the lives of mental health users}

This article intends to discuss the transformative effects of militant and artistic contexts on the daily lives of mental health users. This is an ethnographic research which methodology was based on participant observation and interviews. Data analysis was based on critical and reflexive hermeneutics and phenomenological perspective. We have been able to verify that the engagement in artistic and militant groups resonates strongly in the life-worlds of these people, as well as in the elaboration of their daily life. In these places empathic relationships and alterity are built, and this development is accentuated when the group is gathered, but also has repercussions that exceed this space-time interval. The performative and symbolic elements contribute to the re-elaboration of a being-in-the-world of these subjects and require them to construct a collective scene in which roles, functions, expectations and affections are negotiated; and this process allows them to access from new positions a whole variety of social dramas. So, it is possible to consider these spaces under the therapeutic bias, but we have seen that it is precisely from the denial of this statute that its efficacy comes. Thus, we reinforce the importance of spaces open to the protagonism of the subjects for a psychiatric reform thought as a complex social process.

Keywords: psychosocial attention; expanded clinic; mental health; art; militancy; Anthropology of Experience. 